\title{
Antibacterial hemostatic dressings with nanoporous bioglass containing silver
}

\author{
This article was published in the following Dove Press journal: \\ International Journal of Nanomedicine \\ 2 June 2012 \\ Number of times this article has been viewed
}

\author{
Gangfeng $\mathrm{Hu}^{\prime}$ \\ Luwei Xiao ${ }^{2}$ \\ Peijian Tong ${ }^{2}$ \\ Dawei $\mathrm{Bi}^{\prime}$ \\ Hui Wang' \\ Haitao Ma' \\ Gang Zhu' \\ Hui Liu ${ }^{2}$ \\ 'The First People's Hospital \\ of Xiaoshan, Hangzhou, China; \\ ${ }^{2} Z$ hejiang Traditional Chinese \\ Medical University, Hangzhou, China
}

Correspondence: Peijian Tong

Zhejiang Traditional Chinese Medical University, Hangzhou 310053 , China

Tel +86 057| 82621086

Fax +86 057I 82621086

Email gangfenghu@yahoo.cn
Abstract: Nanoporous bioglass containing silver (n-BGS) was fabricated using the sol-gel method, with cetyltrimethyl ammonium bromide as template. The results showed that n-BGS with nanoporous structure had a surface area of $467 \mathrm{~m}^{2} / \mathrm{g}$ and a pore size of around $6 \mathrm{~nm}$, and exhibited a significantly higher water absorption rate compared with BGS without nanopores. The n-BGS containing small amounts of silver $(\mathrm{Ag})$ had a slight effect on its surface area The n-BGS containing $0.02 \mathrm{wt} \% \mathrm{Ag}$, without cytotoxicity, had a good antibacterial effect on Escherichia coli, and its antibacterial rate reached $99 \%$ in 12 hours. The n-BGS's clotting ability significantly decreased prothrombin time (PT) and activated partial thromboplastin time (APTT), indicating $\mathrm{n}-\mathrm{BGS}$ with a higher surface area could significantly promote blood clotting (by decreasing clotting time) compared with BGS without nanopores. Effective hemostasis was achieved in skin injury models, and bleeding time was reduced. It is suggested that n-BGS could be a good dressing, with antibacterial and hemostatic properties, which might shorten wound bleeding time and control hemorrhage.

Keywords: antibacterial, bioglass, cytotoxicity, dressing, hemostasis, nanopore, silver

\section{Introduction}

In the past decade, many wound-management dressings have been developed, including several dermal- and skin-replacement products and hypertonic saline soaks for the treatment of burned skin, ${ }^{1,2}$ all of which contribute to wound-healing therapy. For example, more than $50 \%$ of all battlefield casualties result from uncontrolled hemorrhaging. ${ }^{3}$ Inorganic oxides with high surface area are attractive for use in medical devices, because these materials are contact activators of the intrinsic pathway of the blood coagulation cascade for inherently polar surfaces. ${ }^{4,5}$ The zeolite-based blood-clotting agent called QuikClot ${ }^{\circledR}$ (Z-Medica Corporation, Wallingford, CT), used for traumatic wound treatments with porous and high-surface-area characteristics, stops high-volume blood loss from large wounds and decreases battlefield mortality. ${ }^{6}$ The dried sterile powder is poured directly on the wound site, where it absorbs water rapidly. One known side effect of the highly exothermic absorption is that the local rise in temperature can cause pain and the burning of tissue. ${ }^{7}$

The synthesis, characterization, and application of nanoporous materials with high specific surface area and high porosity are of particular interest in several fields, such as catalysis support, adsorbents, separation media, sensors, drug delivery support, and oil-spill cleanup. ${ }^{8}$ In biomedical material research, nanoporous materials have been mainly investigated for use in drug delivery. ${ }^{9}$ Recently, room-temperature-synthesized nanoporous bioglasses were studied as bioactive materials for tissue repair; reportedly, 
these bioglasses were biocompatible both in vitro and in vivo. ${ }^{10,11}$

Inflammation, mainly caused by microbial infection, sets in within minutes of a skin injury. In such cases, silver (Ag) ions can have significant antimicrobial effects. ${ }^{12-14}$ However, studies of Ag delivery in the form of nanoporous bioglass containing silver (n-BGS), particularly in terms of its antibacterial application to achieve hemostasis, has not been reported. In this study, a novel biomedical material made of n-BGS that contains Ag ions was developed for potential use in wound-healing applications. Its effects on intrinsic and extrinsic blood clotting systems were examined by testing the activated partial thromboplastin time (APTT) and prothrombin time (PT) in vitro. The high surface area of n-BGS could perform well hemostatically, making it good for incorporation into dressings that require antibacterial properties for achieving hemostasis.

\section{Materials and methods Synthesis of nanoporous bioglass}

Tetraethyl orthosilicate (TEOS), calcium chloride $\left(\mathrm{CaCl}_{2}\right)$, silver nitrate $\left(\mathrm{AgNO}_{3}\right)$, and triethyl phosphate (TEP) were used as precursors of silicon ( $\mathrm{Si})$, calcium (Ca), silver (Ag), and phosphorus (P), respectively. Cetyltrimethyl ammonium bromide was used as the template for making the nanoporous structure of the bioglass. These chemicals (analytical grade) were purchased from Sinopham Chemical Reagent (Shanghai, China).

The n-BGS materials were synthesized according to the following procedures: $2.4 \mathrm{~g}$ cetyltrimethyl ammonium bromide was dissolved in $5 \mathrm{~mL}$ deionized water by stirring at room temperature until the solution became clear; $16 \mathrm{~mL}$ TEOS was then added with vigorous stirring to obtain an inhomogeneous solution. Then, $7.5 \mathrm{~g} \mathrm{CaCl}_{2}, 1.24 \mathrm{~g}$ TEP, and $\mathrm{AgNO}_{3}$ (in various amounts to produce different test solutions) were added. The solution's $\mathrm{pH}$ was maintained in the 8 to 10 range by adding aqueous ammonia, which was also used as catalyst. The synthesized sol-gels, resulting from gelling, aging, and drying the solutions to constant weight, were crackfree. After the reaction, the product was transferred into large surface plates for solvent evaporation at room temperature. The resulting solid was aged at $37^{\circ} \mathrm{C}$ for 5 days. The dried n-BGS samples were heated at the rate of $1^{\circ} \mathrm{C}$ per hour and held isothermally for 6 hours at $600^{\circ} \mathrm{C}$. The samples were then ground and sieved to a grain size of between 50 and $100 \mu \mathrm{m}$. Samples of BGS without nanopores (hereafter, simply BGS) were similarly prepared as controls. The samples were kept refrigerated in sealed containers until use.

\section{Characterization of $n-B G S$ samples}

The surface morphology and microstructure of the n-BGS samples were analyzed using scanning electron microscopy (SEM; JEOL-6360; JEOL, Tokyo, Japan) and transmission electron microscopy (TEM; JEM-2100F; JEOL) working at an acceleration voltage of $200 \mathrm{kV}$. $\mathrm{N}_{2}$ adsorption-desorption isotherms were measured with a porosimeter (TriStar 3000; Micromeritics, Norcross, GA) at $77 \mathrm{~K}$ under a continuous adsorption condition. Brunauer-Emmet-Teller and BarrettJoyner-Halenda (BJH) analyses were done to determine the surface area, pore size, and pore volume.

The water absorption of the n-BGS and BGS samples was determined by weighing the $5 \mathrm{~g}$ samples after soaking in water at $37^{\circ} \mathrm{C}$, and was expressed as a percentage of the initial weight. The water absorption was calculated as water uptake $(\%)=100 \times\left(\mathrm{W}_{\text {wet }}-\mathrm{W}_{0}\right) / \mathrm{W}_{0}$, where $\mathrm{W}_{\text {wet }}$ and $\mathrm{W}_{0}$ represent the weight of the wet and dry material samples, respectively. Values obtained for duplicate samples were averaged.

\section{Cytotoxicity of n-BGS}

L929 cells were used to test the cytotoxicity of n-BGS, which was done by using the n-BGS extracts in contact with L929 cells, according to the relevant International Standards Organization standard (ISO/EN 10993-5). First, a $100 \mathrm{mg} / \mathrm{mL}$ stock solution was prepared by adding $2.5 \mathrm{~g}$ n-BGS (after setting for 2 days and being dried at $50^{\circ} \mathrm{C}$ for $24 \mathrm{~h}$ ) into DMEM culture medium. After incubation at $37^{\circ} \mathrm{C}$ for 24 hours, the mixture was centrifuged and the supernatant was collected. Subsequently, the extracts were sterilized by filtration through $0.2 \mu \mathrm{m}$ filter membranes for cultured cell experiments. The cells were seeded on a 96-well plate and incubated for 24 hours. Then the culture medium was removed and replaced by $50 \mu \mathrm{L}$ of extract and $50 \mu \mathrm{L}$ of DMEM supplemented with 10\% FCS. The DMEM with $10 \%$ FCS (without extract supplement) was used as a blank control. After incubation for 24 hours, the MTT test was used to determine cell viability. Added to each well were $100 \mathrm{~mL}$ of $0.5 \mathrm{mg} / \mathrm{mL} 3$-(4,5)-dimethylthiahiazo(-z-y1)-3,5dipheny-tetrazoliumromide (MTT) solution. After additional incubation for 4 hours, the optical density was measured by a microplate reader at the wavelength of $492 \mathrm{~nm}$.

\section{$\mathrm{Ag}$ ion release from $\mathrm{n}-\mathrm{BGS}$}

$\mathrm{Ag}$ ion release from $\mathrm{n}-\mathrm{BGS}$ (with BGS as control) into a phosphate buffer solution (PBS) was tested using an inductively coupled plasma atomic emission spectrometer (ICP-AES; Optima 2000 TM; PerkinElmer, Waltham, MA). $\mathrm{Ag}$ ion release was measured at different time points and 
the Ag ion concentration determined. Each n-BGS and BGS $0.2 \mathrm{~g}$ sample was immersed in $20 \mathrm{~mL}$ PBS. The postimmersion solutions obtained at $0.5,1,2,3,6,12,18$, and 24 hours were analyzed for Ag ion release by using ICP.

\section{Antibacterial performance of $n-B G S$}

The antibacterial performance against Escherichia coli (E. coli) was determined by the plate-counting method. ${ }^{15}$ Seventy-percent ethanol was used to sterilize the n-BGS and BGS samples, then a $0.4 \mathrm{mg}$ sample was added into a $0.04 \mathrm{~mL}$ solution of bacteria $\left(3.25 \times 10^{4} \mathrm{CFU} \mathrm{mL}^{-1}\right)$ and covered by a polyethylene film $(15 \times 15 \mathrm{~mm})$. At a relative humidity over $90 \%$ and a temperature of $37^{\circ} \mathrm{C}$, the bacteria on the n-BGS and BGS samples were incubated for 24 hours. After that, they were thoroughly washed with $10 \mathrm{~mL}$ of a $0.87 \% \mathrm{NaCl}$ solution that contained Tween 80 with a $\mathrm{pH}$ of 7.0. To observe the living bacteria, $0.2 \mathrm{~mL}$ of the washing solution was added into the different dishes containing the nutrient agar. After incubation under similar conditions for 1 hour and 24 hours, respectively, the active bacteria were counted; each evaluation was done in triplicate, and the values obtained were averaged to give the final data. The antibacterial effect was quantitatively determined using the following relationship: $\mathrm{R}(\%)=100 \times(\mathrm{B}-\mathrm{C}) / \mathrm{B}$, where $\mathrm{R}$ is the antibacterial effect $(\%), \mathrm{B}$ is the mean number of bacteria on the control samples (CFU/sample), and $\mathrm{C}$ is the mean number of bacteria on the modified samples (CFU/sample).

\section{In vitro hemostatic assay}

The PT and APTT measurements were done using a semi-automatic coagulation analyzer (bioMérieux, Marcy l'Etoile, France). This was done to determine the effects of the n-BGS samples on blood-clotting time and to observe the hemostatic effect of n-BGS. The study was approved by the Research Center for Drug Safety Evaluation of the Shanghai University of Traditional Chinese Medicine. Blood samples were taken from Sprague-Dawley rats and mixed with one-tenth volume of $3.8 \%$ sodium citrate. The platelet-poor plasma was obtained by centrifugation at $2500 \mathrm{~g}$ for 15 minutes at $37^{\circ} \mathrm{C}$.

The PT test was performed on $50 \mathrm{~mL}$ of citrated plasma and $100 \mathrm{~mL}$ of PT reagent. The samples were incubated at $37^{\circ} \mathrm{C}$ for 3 minutes. The PT reagent and n-BGS sample were added to the plasma in the test tube, and PT was measured simultaneously. The APTT test was performed by adding $50 \mathrm{~mL}$ of APTT reagent to $50 \mathrm{~mL}$ of citrated plasma. After incubation at $37^{\circ} \mathrm{C}$ for 5 minutes, $50 \mathrm{~mL}$ of $0.025 \mathrm{~mol} / \mathrm{L}$ $\mathrm{CaCl}_{2}$ and the n-BGS and BGS samples were put in the test tube, and APTT was measured simultaneously. The PT and APTT tests were done for both n-BGS and BGS samples, including a control sample (no material was added to the plasma), for each test run, according to the PT and APTT kit instructions (Sun Biotechnology Co, Shanghai, China).

\section{Hemostasis in an animal model}

Male New Zealand white rabbits were purchased from Shanghai Silaike (Shanghai, China) and fasted for 36 hours before the experiment. The n-BGS, BGS, and control (no materials added) were used in this experiment. Before the experiments, the materials were dried at $150^{\circ} \mathrm{C}$ in vacuum for 5 hours and were sterilized by UV irradiation for 3 hours. Rabbits were anesthetized by intravenous injection of sodium pentobarbital $(45 \mathrm{mg} / \mathrm{kg})$ and were placed on their backs to expose the groin with their hind limbs extended. The thigh soft tissues, including skin and overlying muscles, were transected with a scalpel to expose the femoral artery and vein. A severe injury was created by cutting the femoral artery and vein completely to produce uncontrolled hemorrhage. The blood was then immediately and continuously suctioned from the inguinal cavity before the n-BGS was applied over the injury site. Manual compression on the wound site was needed until the bleeding was stopped. The same area was observed 15 seconds after application of the n-BGS to the location of the cut. Controls were treated with pressure using standard gauze. At the end of the study period, each groin was opened and the liquid and clotted inguinal blood and materials were suctioned and measured.

\section{Statistical analysis}

Statistical analysis was performed using Student's t-test. The results for each experiment are expressed as the mean \pm standard deviation. Differences were considered statistically significant at $P<0.05$.

\section{Results and discussion Surface morphology and microstructure of $n-B G S$}

The n-BGS, with $0.02 \mathrm{wt} \% \mathrm{Ag}$ content, was synthesized successfully according to our experimental procedure. The n-BGS surface morphology and microstructure was observed by SEM and TEM. The surface morphology of n-BGS is shown in Figure 1A, in which n-BGS with $0.02 \mathrm{wt} \% \mathrm{Ag}$ content is in granule shapes, sized $2-5 \mu \mathrm{m}$ in diameter. In addition, in the TEM image (Figure 1B), a uniform nanoporous structure with well-ordered pores can be observed. Supramolecular chemistry has allowed the design and 

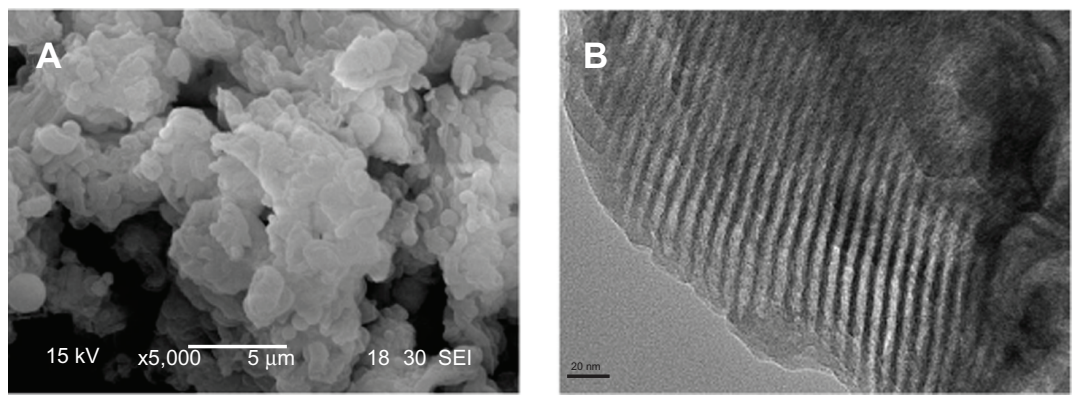

Figure I SEM (A) and TEM (B) images of nanoporous bioglass containing silver, with 0.02 wt\% Ag content. Abbreviations: Ag, silver; SEM, scanning electron microscopy; TEM, transmission electron microscopy.

synthesis of nanoporous materials with fascinating textural and structural features that open many paths for research into biomedical materials for tissue repair. ${ }^{16}$

\section{Surface area and pore size of n-BGS}

The nitrogen adsorption-desorption isotherm and the $\mathrm{BJH}$ adsorption of n-BGS with $0.02 \mathrm{wt} \% \mathrm{Ag}$ content are shown in Figure 2. The nitrogen adsorption-desorption isotherm of n-BGS shows an adsorption at low pressures, an increase in adsorption with increasing pressure, and hysteresis upon desorption. The isotherm characteristics reflect type IV isotherms typical for nanoporous materials. ${ }^{17}$ The nanopore size of n-BGS ranges from $2 \mathrm{~nm}$ to $10 \mathrm{~nm}$, according to the Brunauer-Deming-Deming-Teller classification. ${ }^{20}$ Corresponding to the nitrogen adsorption-desorption isotherm, the BJH adsorption shows the distribution of pore volume and pore diameter. It was calculated that the specific surface area and mean pore diameter of n-BGS were $467 \mathrm{~m}^{2} / \mathrm{g}$ and $6 \mathrm{~nm}$, while the surface area of BGS was $91 \mathrm{~m}^{2} / \mathrm{g}$. The pore size distribution of n-BGS is shown in Figure 2B, which shows uniform nanoporous structure of the materials. The nitrogen sorption result was consistent with the TEM image of n-BGS.

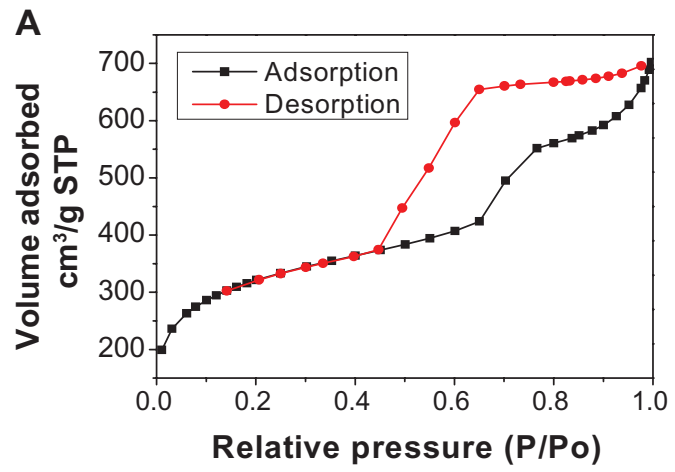

In Table 1, the effects of the Ag content on the surface area and pore size of n-BGS are summarized, and the n-BGS samples with $0.01,0.02,0.03$, and $0.04 \mathrm{wt} \%$ $\mathrm{Ag}$ content are shown. The results show that the addition of Ag to n-BGS had a slight effect on its surface area $\left(418-483 \mathrm{~m}^{2} / \mathrm{g}\right)$; it can be seen that the surface area slightly decreased with the increase of Ag content in the n-BGS. However, there was no observed effect of $\mathrm{Ag}$ content on $\mathrm{n}$-BGS pore size $(6 \mathrm{~nm})$.

\section{Water adsorption of $n-B G S$}

Water adsorption of n-BGS and BGS samples is shown in Figure 3. It was found that the water absorption rate of n-BGS (71\%) with $0.02 \mathrm{wt} \% \mathrm{Ag}$ content was higher than that of BGS $(22 \%)(P<0.05)$. However, no differences were found among n-BGS samples with $0.01,0.02,0.03$, and $0.04 \mathrm{wt} \% \mathrm{Ag}$ content. The results show that the surface area of the n-BGS samples had significant effects on their water adsorption. The $\mathrm{n}-\mathrm{BGS}$ with $0.02 \mathrm{wt} \% \mathrm{Ag}$ content had a surface area of $467 \mathrm{~m}^{2} / \mathrm{g}$, which was obviously higher than that of BGS at $91 \mathrm{~m}^{2} / \mathrm{g}(P<0.05)$. The results show that n-BGS can absorb a large amount of water because of its high surface area.

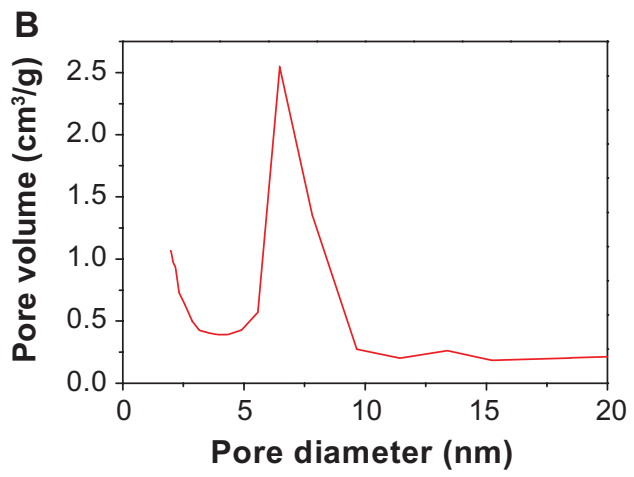

Figure 2 Nitrogen adsorption-desorption isotherms (A) and pore size distribution (B) of nanoporous bioglass containing silver, with 0.02 wt\% $\mathrm{Ag}$ content. Abbreviation: $\mathrm{Ag}$, silver. 
Table I Effect of Ag content on surface area and pore size of nanoporous bioglass containing silver

\begin{tabular}{lll}
\hline Ag content & Surface area $\left(\mathbf{m}^{2} / \mathbf{g}\right)$ & Arranged pore size $(\mathbf{n m})$ \\
\hline $0.01 \mathrm{wt} \%$ & 483 & 6 \\
$0.02 \mathrm{wt} \%$ & 467 & 6 \\
$0.03 \mathrm{wt} \%$ & 443 & 6 \\
$0.04 \mathrm{wt} \%$ & 418 & 6 \\
\hline
\end{tabular}

Abbreviation: $\mathrm{Ag}$, silver

\section{$\mathrm{Ag}$ ion release into PBS}

Figure 4 shows the amounts of Ag ions released into the PBS from n-BGS and BGS containing $0.02 \mathrm{wt} \% \mathrm{Ag}$ content at different time points. The Ag ion concentrations in the PBS for both the n-BGS and BGS samples increased gradually with time during the soaking period. This increase was due to the release of $\mathrm{Ag}$ ions from $\mathrm{n}-\mathrm{BGS}$ and $\mathrm{BGS}$, according to the ICP analysis. As for Ag ion release, the Ag ion concentrations in the PBS increased slightly quicker for n-BGS than for BGS during the first 12 hours, indicating that $\mathrm{Ag}$ ions are easily distributed on the surface of the material, owing to the high surface area of n-BGS. However, for Ag ions concentrations in PBS, it was found that no obvious differences existed between the n-BGS and BGS samples at the end of 24 hours. The results show that the nanoporous structure had no obvious effect on Ag release into the PBS, either from the n-BGS or the BGS samples.

\section{Antibacterial property of n-BGS}

In this study, E. coli was used to assess the antibacterial property of n-BGS. The antibacterial rate of n-BGS against E. coli over time is shown in Figures 5 and 6 . The results reveal that the antibacterial rate of n-BGS increased with the increase of Ag content both at 1 hour and 12 hours. The antibacterial experiments clearly indicate that the addition of Ag into n-BGS enhanced its antibacterial properties, and the

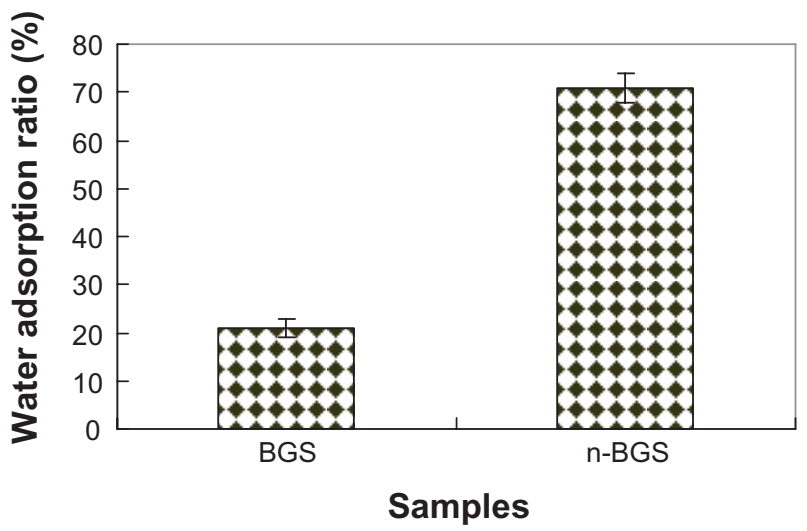

Figure 3 Water adsorption of nanoporous bioglass containing silver (n-BGS), and BGS without nanopores as a control.

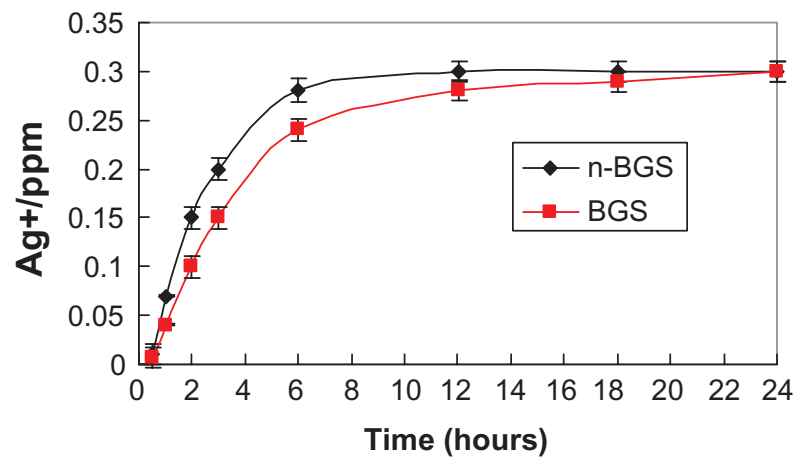

Figure $4 \mathrm{Ag}$ ions release from nanoporous bioglass containing silver (n-BGS), and BGS without nanopores, with $0.02 \mathrm{wt} \% \mathrm{Ag}$ content into PBS ( $\mathrm{pH} 7.4)$ over time. Abbreviations: Ag, silver; BGS, bioglass containing silver; ppm, parts per million.

antibacterial rate depended significantly on the Ag content in $\mathrm{n}-\mathrm{BGS}$. Therefore, the results show that the Ag content is an important factor to be considered when designing woundhealing agents, due to the ubiquitous role of Ag ions, which have antibacterial activity.

The antibacterial rate of $\mathrm{n}-\mathrm{BGS}$ with $0.01 \mathrm{wt} \% \mathrm{Ag}$ was $56 \%$ and $83 \%$ at 1 hour and 12 hours, respectively, while the antibacterial rate of $\mathrm{n}-\mathrm{BGS}$ with $0.02 \mathrm{wt} \% \mathrm{Ag}$ was $75 \%$ and $99 \%$ at 1 hour and 12 hours, respectively. Therefore, we chose $\mathrm{n}$-BGS with $0.02 \mathrm{wt} \% \mathrm{Ag}$ content as the right sample for other experiments, because a higher Ag content might cause cytotoxicity.

The antibacterial ability of n-BGS is related to two main factors. One is that the positive charges of materials can absorb a large number of cells with negative charges on their surface from the solution; this can then destroy the energy metabolism, respiration, and electronic transmission systems of the cells: contact with the $-\mathrm{SH}$ and $-\mathrm{NH}_{2}$ ions of proteins on cell membrane surfaces causes bacterial death. ${ }^{18}$ The other factor is that Ag ions released from samples may bind with DNA molecules and cause disordering of the helical structure

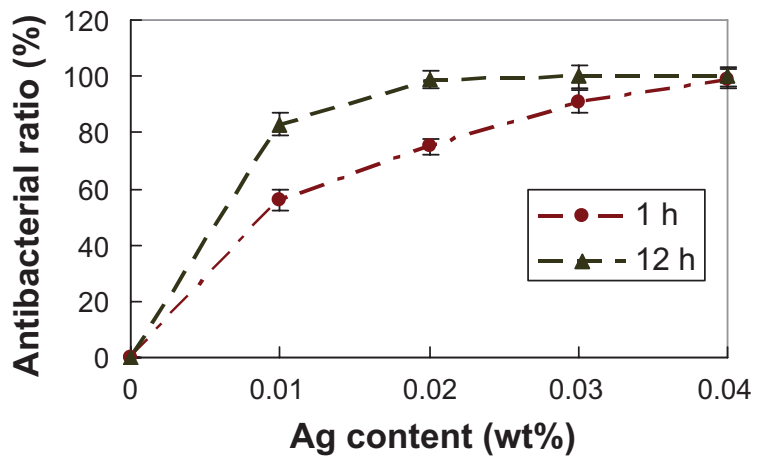

Figure 5 Effects of $\mathrm{Ag}$ amounts on antibacterial property of nanoporous bioglass containing silver against Escherichia coli incubation for I hour and I2 hours. Abbreviation: $\mathrm{Ag}$, silver. 

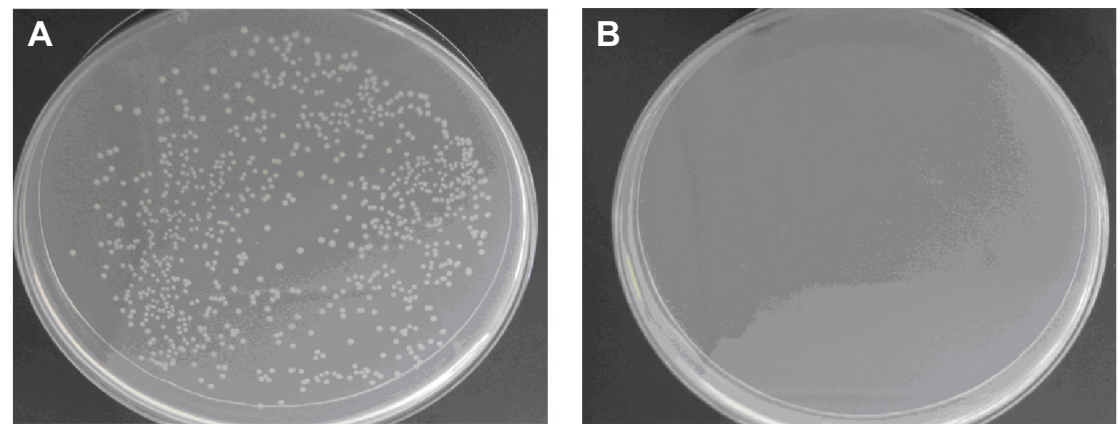

Figure 6 Antibacterial effects of nanoporous bioglass containing silver (n-BGS) against Escherichia coli at I2 hours (A), and non-nanoporous BGS (B) as a control.

through cross-linking within and between the nucleic acid strands. ${ }^{19}$ Therefore, biochemical processes can also be disrupted by $\mathrm{Ag}$ ions inside bacterial cells. The reason for the greater sensitivity of $E$. coli to n-BGS containing Ag may be attributed to the greater abundance of amines and carboxyl groups on the cell surface of $E$. coli and to the greater affinity of Ag toward these groups. ${ }^{20}$

\section{Cytotoxicity of n-BGS}

The cytotoxicity of n-BGS was determined by using the extracts of n-BGS cultured with L929 cells for 24 hours, according to ISO/EN 10993-5. The effects of n-BGS extracts with different concentrations on L929 cells are shown in Figure 7; within a broad extract concentration range $(25-200 \mathrm{mg} / \mathrm{mL})$, cell viability exceeds that of the blank control. For many years, BGS, with its excellent biocompatibility, has been applied as a biomaterial for bone repair in clinics. Our results show that extracts of n-BGS cause no cytotoxicity to L929 cells, satisfying the relevant criteria for biomaterials and indicating n-BGS has good cytocompatibility.

As to the use of n-BGS biomaterials for tissue repair, n-BGS's biocompatibility and biosecurity are

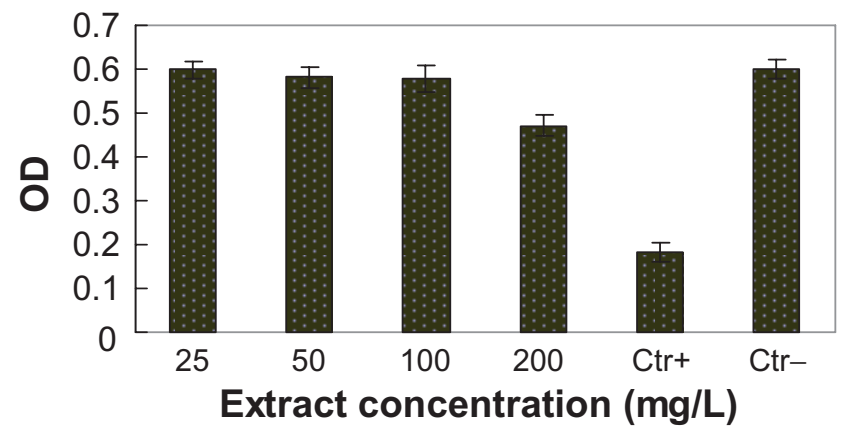

Figure 7 Effects of bioglass containing silver extracts on L929 cells cultured for 24 hours, which showed the cytotoxicity of nanoporous bioglass containing silver. Abbreviation: OD, optical density. very important. Biomedical alloys with a variety of noble elements have been found to be more biocompatible, even when they contain a significant amount of $\mathrm{Ag} .{ }^{21}$ Tests of their direct surface contact with cells showed that cells could grow better on $\mathrm{Ag}-\mathrm{TiO}_{2}$ coatings. $\mathrm{Ag}-\mathrm{TiO}_{2}$ coatings also had higher antibacterial properties, with tolerable cytocompatibility. ${ }^{22}$ A study showed that the surface antibacterial property and biocompatibility of biopolymers can be enhanced by means of plasma immersion ion implantation (PIII). Based on cell assays, the Ag PIII polyethylene samples exhibited excellent biocompatibility for cells, demonstrating that Ag PIII not only enhances antibacterial properties but also improves the cell biocompatibility of polyethylene. ${ }^{23}$

\section{Hemostatic performance of $n-B G S$}

Figure 8 shows the clotting time of n-BGS and BGS, measured using the PT and APTT assays. The results display the effects of a nanoporous structure on the hemostatic activity of n-BGS. It was found that the APTT and PT for n-BGS with a high surface area were much shorter than for BGS or the blank control, indicating that the surface area of the samples had a significant influence on the clotting time.

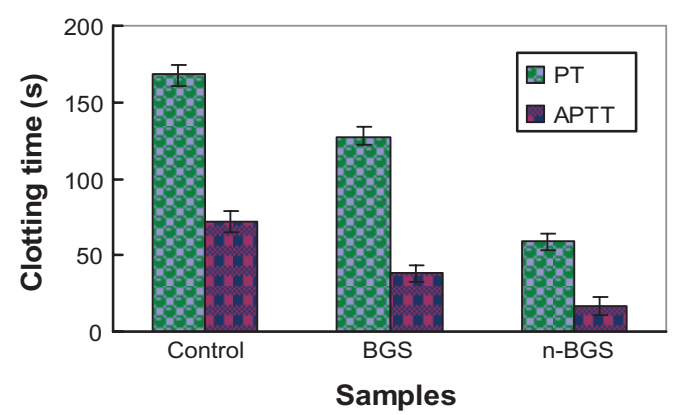

Figure 8 Clotting time of the nanoporous bioglass containing silver (n-BGS) and non-nanoporous BGS measured using the prothrombin time (PT) and activated partial thromboplastin time (APTT) assays, and without material as a control. 

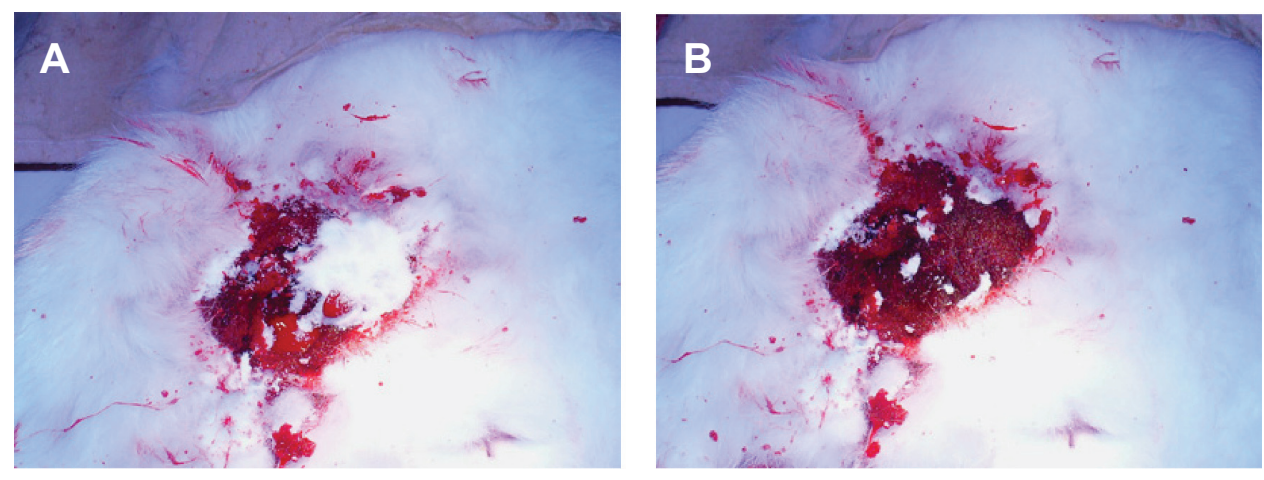

Figure 9 Comparison of hemostasis in rabbit skin injury (control wound bleeding): nanoporous bioglass containing silver (n-BGS) (A) and non-nanoporous BGS (B).

Prospectively, n-BGS can be applied as a hemostatic agent for traumatic wound treatments, to stop high-volume blood loss from large wounds.

It was reported that molecular sieve material can promote blood clots, since it can absorb a large amount of water from the blood because of its high surface area. ${ }^{24}$ The n-BGS in this study has a structure and chemical composition similar to that of molecular sieve material, and our results demonstrated that the surface area of n-BGS also had obvious effects on clotting time.

The surface area of $\mathrm{n}-\mathrm{BGS}$ with $0.02 \mathrm{wt} \% \mathrm{Ag}$ content $\left(467 \mathrm{~m}^{2} / \mathrm{g}\right)$ was obviously higher than that of BGS $\left(91 \mathrm{~m}^{2} / \mathrm{g}\right)$, and therefore the APTT and PT were significantly shorter for n-BGS than BGS or the blank control sample (without material; $P<0.05$ ). In addition, n-BGS did not produce superheating, compared with molecular sieve material (such as QuikClot), ${ }^{6}$ in the hemostatic process, since n-BGS exerts a hemostatic effect on blood mainly in a physical adsorption process, but not in a chemical reaction process. ${ }^{7}$ In conclusion, n-BGS with appropriate $\mathrm{Ag}$ amounts in this study had good antibacterial properties and biocompatibility, and indicated its potential for use in wound-healing applications.

\section{Hemostasis of $n-B G S$ in skin injury}

The skin injuries of rabbits $(n=12)$ were surgically exposed, transected, and treated with n-BGS (Figure 9). The time to produce complete hemostasis in different experimental groups was then recorded (Figure 10). After $27 \pm 2.0$ seconds ( $\mathrm{n}-\mathrm{BGS}, \mathrm{n}=4$ ) and $86 \pm 3$ seconds (BGS, $\mathrm{n}=4$ ), hemostasis occurred in the two sample-treated groups, whereas the control group $(n=4)$ prolonged the time to $193 \pm 8$ seconds. The results showed that the bleeding time for n-BGS was obviously shorter than for BGS, indicating that the high surface area afforded by the nanoporous structure of n-BGS had better hemostatic activity than did BGS without nanopores. Both the n-BGS- and BGS-treated groups had significantly $(P<0.05)$ better performance (less time to hemostasis) than had the control group. Furthermore, the material adherence strength was observed to be higher in the n-BGS than in the BGS group, indicating that hemostasis is likely related to the adhesiveness of the materials.

Effective bleeding control is currently becoming increasingly important in military and civilian trauma cases since it can significantly reduce mortality. Our results suggest that n-BGS is effective in activating the intrinsic pathway of the coagulation cascade, promoting blood clotting, and achieving hemorrhage control in animal models, all of which indicate n-BGS's hemostatic properties. Therefore, n-BGS's high surface area possesses greater hemostatic performance than do some biomaterials for hemorrhage control already on the market (HemCon, Traumastatt, etc). ${ }^{2-4}$ The chemical and physical parameters, such as surface area, nanoporous architecture, and the form of agent dosage, have all been considered important mechanistic elements in the enhanced hemostatic properties of n-BGS. None of these factors individually provides a sufficient mechanistic explanation, however, because effective hemostasis is achieved by the synergism of all these factors.

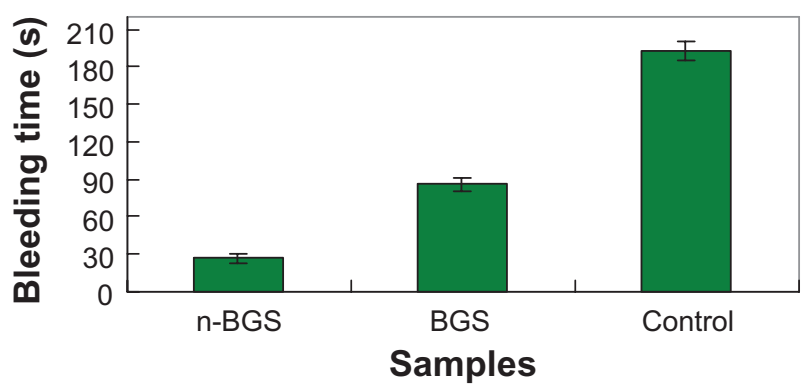

Figure 10 Comparison of the bleeding time of rabbit skin injury after using nanoporous bioglass containing silver (n-BGS), non-nanoporous BGS, and without material (control). 


\section{Conclusion}

Nanoporous bioglass containing antibacterial silver (n-BGS) was synthesized by the sol-gel method, which yielded n-BGS granules with the high surface area of $467 \mathrm{~m}^{2} / \mathrm{g}$ and a pore size of about $6 \mathrm{~nm}$. The high specific surface area and nanoporous structure of n-BGS resulted in a significantly higher water-absorption rate than that of non-nanoporous BGS. The surface area of n-BGS slightly decreased with the increase in the amount of $\mathrm{Ag}$, which had no obvious effect on the pore size of n-BGS.

The antibacterial property of n-BGS significantly was enhanced by increasing the Ag amounts that were released. The n-BGS without cytotoxicity, containing $0.02 \mathrm{wt} \% \mathrm{Ag}$, had good antibacterial properties against $E$. coli, with an antibacterial rate reaching $75 \%$ in 1 hour and $99 \%$ in 12 hours. The clotting APTT and PT was significantly shortened for n-BGS, as compared with BGS, indicating that n-BGS has superior thermostatic properties. The n-BGS effectively promoted blood clotting and achieved hemorrhage control in the animal model. Its high surface area results in excellent hemostatic performance because it can absorb a large amount of water from the blood, which concentrates the blood components and reduces clotting time.

\section{Disclosure}

The authors report no conflicts of interest in this work.

\section{References}

1. Humphreys MR, Castle EP, Andrews PE, Gettman MT, Ereth MH. Microporous polysaccharide hemospheres for management of laparoscopic trocar injury to the spleen. Am J Sur. 2008;195(1):99-103.

2. Sohn VY, Eckert MJ, Martin MJ, et al. Efficacy of three topical hemostatic agents applied by medics in a lethal groin injury model. J Surg Res. 2009;154(2):258-261.

3. Alam HB, Burris D, DaCorta JA, Rhee P. Hemorrhage control in the battlefield: role of new hemostatic agents. Mil Med. 2005;170(1): 63-69.

4. Bjorsesa K, Holst J. Various local hemostatic agents with different modes of action: an in vivo comparative randomized vascular surgical experimental study. Eur J Vasc Endovasc. 2007;33(3):363-370.

5. Ostomel TA, Shi Q, Stoimenov PK, Stucky GD. Metal oxide surface charge mediated hemostasis. Langmuir. 2007;23(22):11233-11238.

6. Arnaud F, Tomori T, Carr W, et al. Exothermic reaction in zeolite hemostatic dressings: QuikClot ACS and ACS+. Ann Biomed Eng. 2008;36(10):1708-1713.
7. Ostomel TA, Stoimenov PK, Holden PA, Alam HB, Stucky GD. Hostguest composites for induced hemostasis and therapeutic healing in traumatic injuries. J Thromb Thrombolysis. 2006;22(1):55-67.

8. Kumar P, Guliants VV. Periodic mesoporous organic-inorganic hybrid materials: applications in membrane separations and adsorption. Micropor Mesopor Mat. 2010;132(1-2):1-14.

9. Wei J, Chen F, Shin JW, et al. Preparation and characterization of bioactive mesoporous wollastonit-polycaprolactone composite scaffold. Biomaterials. 2009;30(6):1080-1088

10. Mahony O, Jones JR. Porous bioactive nanostructured scaffolds for bone regeneration: a sol-gel solution. Nanomedicine. 2008;3(2):233-245.

11. Hong Y, Chen X, Jing X, et al. Preparation, bioactivity, and drug release of hierarchical nanoporous bioactive glass ultrathin fibers. Adv Mater. 2010;22(6):754-759.

12. Percival SL, Bowler PG, Russell D. Bacterial resistance to silver in wound care. J Hospl Infect. 2005;60(1):1-7.

13. Rastogi SK, Rutledge VJ, Gibson C, Newcombe DA, Branen JR, Branen AL. Ag colloids and Ag clusters over EDAPTMS-coated silica nanoparticles: synthesis, characterization and antibacterial activity against Escherichia coli. Nanomed Nanotechnol. 2011;7(3):305-314.

14. Ansari MA, Khan HM, Khan AA, et al. Evaluation of antibacterial activity of silver nanoparticles against MSSA and MRSA on isolates from skin infections. Biol Med. Special Issue: 2011;3(2):141-146.

15. Quang DV, Sarawade PB, Hilonga A, et al. Preparation of silver nanoparticle containing silica micro beads and investigation of their antibacterial activity. Appl Surf Sci. 2011;257(15):6963-6970.

16. Ecija D, Seufert K, Heim D, et al. Hierarchic self-assembly of nanoporous chiral networks with conformationally flexible porphyrins. Acs Nano. 2010;4(8):4936-4942.

17. Li X, Zhang L, Dong X, et al. Preparation of mesoporous calcium doped silica spheres with narrow size dispersion and their drug loading and degradation behavior. Micropor Mesopor Mat. 2007;102(1-3):151-158.

18. Choi O, Deng KK, Kim NJ, Ross L Jr, Surampalli RY, Hu Z. The inhibitory effects of silver nanoparticles, silver ions, and silver chloride colloids on microbial growth. Water Res. 2008;42(12):3066-3074.

19. Banerjee M, Sharma S, Chattopadhyay A, Ghosh SS. Enhanced antibacterial activity of bimetallic gold-silver core-shell nanoparticles at low silver concentration. Nanoscale. 2011;3(12):5120-5125.

20. Dai C, Yuan Y, Liu C, et al. Degradable, antibacterial silver exchanged mesoporous silica spheres for hemorrhage control. Biomaterials. 2009;30(29):5364-5375.

21. Silver S. Bacterial silver resistance: molecular biology and uses and misuses of silver compounds. FEMS Microbiol Rev. 2003;27(2-3):341-353.

22. Chen Y, Zheng X, Xie Y, Ding C, Ruan H, Fan C. Anti-bacterial and cytotoxic properties of plasma sprayed silver-containing HA coatings. J Mater Sci Mater Med. 2008;19(12):3603-3609.

23. Zhang W, Luo Y, Wang H, Jiang J, Pu S, Chu PK. Ag and Ag/N(2) plasma modification of polyethylene for the enhancement of antibacterial properties and cell growth/proliferation. Acta Biomater. 2008;4(6):2028-2036

24. Ferraz N, Carlsson J, Hong J, Ott MK. Influence of nanopore size on platelet adhesion and activation. J Mater Sci Mater Med. 2008;19(9):3115-3121.
International Journal of Nanomedicine

\section{Publish your work in this journal}

The International Journal of Nanomedicine is an international, peerreviewed journal focusing on the application of nanotechnology in diagnostics, therapeutics, and drug delivery systems throughout the biomedical field. This journal is indexed on PubMed Central, MedLine, CAS, SciSearch $\AA$, Current Contents ${ }^{\circledR} /$ Clinical Medicine,

\section{Dovepress}

Journal Citation Reports/Science Edition, EMBase, Scopus and the Elsevier Bibliographic databases. The manuscript management system is completely online and includes a very quick and fair peer-review system, which is all easy to use. Visit http://www.dovepress.com/ testimonials.php to read real quotes from published authors. 